\title{
IMPLEMENTASI METODE AHP DAN TOPSIS UNTUK PENILAIAN KARYAWAN BARU DI CV. ORIGINALITY GROUP BERBASIS WEB
}

\author{
Ruslin Samsaudin, Yosep Agus Pranoto, Mira Orisa \\ Program Studi Teknik Informatika S1, Fakultas Teknologi Industri \\ Institut Teknologi Nasional Malang, Jalan Raya Karanglo km 2 Malang, Indonesia \\ Samsaudinruslin86@gmail.com
}

\begin{abstract}
ABSTRAK
Penilaian kinerja karyawan ialah evaluasi kinerja dari karyawan atau penilaian karyawan, keterampilan dan kemampuan, dan melihat perkembangan dari karyawan. Kegiatan ini perlu dilakukan setiap perusahaan agar bisa mengevaluasi kinerja dan untuk meningkatkan produktivitas dari karyawan. Permasalahan yang timbul dari proses penilaian adalah bagaimana menghasilkan penilaian karyawan terbaik berdasarkan kriteria yang ada dengan mengerjakan penilaiannya menggunakan beberapa metode. Maka dari itu peneliti menggunakan beberapa metode dalam penilaian, sehingga dapat menetapkan metode yang cocok dengan tingkat akurasi yang lebih baik dalam pengambilan keputusan penilaian. Dari kasus di atas maka penulis berkeinginan membuat suatu sistem pendukung keputusan penilaian karyawan yang sesuai dengan kriteria yang ada. Aplikasi yang dirancang ini menggunakan metode AHP dan TOPSIS. Kelemahan dari metode TOPSIS adalah memerlukan bobot pada proses perangkingannya. Oleh karena itu, perlu dilakukan penggabungan metode lain dengan metode AHP untuk mendapatkan hasil yang lebih efektif. Kombinasi metode AHP dan TOPSIS dipilih karena metode AHP didasarkan pada keunggulan matriks pembanding dan dapat melakukan analisis konsistensi. Hasil pengujian akurasi Dapat disimpulkan untuk metode AHP-TOPSIS pada penialaian karyawan dengan uji akurasi confusion matrix nilai yang sesuai terdapat 8 (TP), untuk nilai klasifikasi yang salah adalah 2 (FP), nilai dari FN adalah 0 dan untuk nilai TN yaitu 0 sehingga didapatkan nilai akurasi dari hasil perhitungan yaitu $80 \%$ Accuracy. Sedangkan untuk pengujian fungsionalitas pada aplikasi implementasi metode AHP dan TOPSIS untuk seleksi calon karyawan baru pada CV. Originality Group dapat dijalankan dengan baik pada browser web. Berdasarkan hasil pengujian aplikasi dengan menggunakan 2 browser yang berbeda, semua tampilan dan fungsi aplikasi dapat berjalan 100\% pada 2 browser yaitu, Microsoft Edge Version 91.0.864.54 (Official build) (64-bit) dan Google Chrome Versi 91.0.4472.114 (Build Resmi) (64 bit)
\end{abstract}

Kata Kunci : AHP-TOPSIS, Seleksi, Sistem Pendukung Keputusan, Karyawan

\section{PENDAHULUAN}

Karyawan ialah tenaga kerja yang melakukan pekerjaan pada setiap bentuk usaha (perusahaan) atau perorangan untuk melakukan operasional tempat kerjanya dengan balas jasa berupa uang. Setiap perusahaan, sumber daya manusia ialah assets yang sangat penting. Adanya skill dan keahlian yang bagus dari sumber dayaa manusia yang dipunyai, maka perusahaan akan dapat mengalamii kemajuan. Untuk memotivasi kinerja karyawannya, CV Originality Group melakukan penilaian karyawan. Manajer melakukan penilaian karyawan perusahaan dari sebagian kriteria. Kriteria yaang digunakan dalam penilaian karyawan yaitu, sikap dan perilaku, disiplin dan bertanggung jawab, pengalaman kerja, keahlian, usia.

Permasalahan yang timbul dari proses penilaian adalah bagaimana menghasilkan penilaian karyawan terbaik berdasarkan kriteria yang ada dengan mengerjakan penilaiannya menggunakan beberapa metode. Maka dari itu peneliti menggunakan beberapa metode dalam penilaian, sehingga dapat menetapkan metode yang cocok dengan tingkat akurasi yang lebih baik dalam pengambilan keputusan penilaian.
Penilaian kinerja karyawan ialah evaluasi kinerja dari karyawan atau penilaian karyawan, keterampilan dan kemampuan, dan melihat perkembangan dari karyawan. Kegiatan ini perlu dilakukan setiap perusahaan agar bisa mengevaluasi kinerja dan untuk meningkatkan produktivitas dari karyawan.

Dari kasus di atas maka penulis berkeinginan membuat suatu sistem pendukung keputusan penilaian karyawan baru yang sesuai dengan kriteria yang ada. Aplikasi yang dirancang ini menggunakan AHP dan TOPSIS. Kelemahan dari metode TOPSIS adalah memerlukan bobot pada proses perangkingannya. Oleh karena itu, perlu dilakukan penggabungan metode lain dengan metode AHP untuk mendapatkan hasil yang lebih efektif. Kombinasi metode AHP dan TOPSIS dipilih karena metode AHP didasarkan pada keunggulan matriks pembanding dan dapat melakukan analisis konsistensi. Dengan melakukan penggabungan metode AHP, serta TOPSIS diharapkan dapat menghasilkan rekomendasi yang lebih baik. Sistem pendukung keputusan penilaian karyawan baru ini akan secara otomatis memberikan rekomendasi 
karyawan dengan nilai tinggi berdasarkan kriteria yang ada.

Keunggulan dari aplikasi yang telah dibuat adalah dapat memudahkan dalam pengambilan keputusan untuk mengevaluasi kinerja karyawan untuk meningkatkan produktivitas karyawan agar perusahaan dapat mengalami kemajuan.

\section{TINJAUAN PUSTAKA}

\subsection{Penelitian Terdahulu}

Achmad Sidik (2021) pada penelitian dengan judul "Implementasi AHP TOPSIS Alternatif Penentuan Jabatan di STMIK GLOBAL". Tujuan penelitian ini yaitu dalam penentuan jabatan terdapat beberapa kriteria yang digunakan yaitu kriteria tingkat pendidikan, masa kerja, linieritas, publikasi per tahun, Toelf. Konsepnya adalah membandingkan kompetensi individu dengan kompetensi pekerjaan sehingga terlihat perbedaan kompetensi (disebut juga gap), semakin kecil hasilnya maka semakin tinggi bobot nilai yang artinya semakin besar peluang seseorang untuk menduduki posisi tersebut.

Silvi Dwi Megafani (2021) pada penelitian dengan judul "Sistem Pendukung Keputusan Perekrutan Anggota Baru Resimen Mahasiswa Di Itn Malang Menggunakan Kombinasi Metode Ahp Dan Topsis". Tujuan penelitian ini yaitu sistem pendukung keputusan penerimaan anggota Menwa baru menggunakan metode AHP dan TOPSIS. Metode AHP ini digunakan pada proses awal yaitu menentukan bobot dari setiap kriteria dan langkah selanjutnya menggunakan metode TOPSIS yang digunakan untuk menentukan nilai dari tiap calon anggota untuk melakukan proses perangkingan

\subsection{Gambaran Umum Perusahaan}

CV. Originality Group Di mulai pada tahun 2011 di Yogyakarta, perusahaan yang bergerak di bidang industri konveksi atau garment ini terus tumbuh dan berkembang, hingga pada saat ini kami berpindah lokasi dan terpusat di Pa, Jawa Tengah, Indonesia mulai tahun 2016. Strategi pertumbuhan kami di bangun di atas janji untuk memberikan produk berkualitas dan layanan unggulan dengan harga yang terbaik. Perusahaan kami mengolah bahan baku yang berupa kain menjadi pakai jadi, seap proses kami kerjakan sendiri mulai dari memotong, menyablon, membordir, menjahit, hingga finishing dan siap untuk di pakai pelanggan. Visi perusahaan adalah menjadi produsen pakaian jadi yang terbaik dalam hal kualitas produk dan layanan di industri lokal maupun internasional. Misi perusahaan adalah menjadi mitra anda untuk pemenuhan kebutuhan pakaian jadi berkualitas nggi di pasar lokal maupun internasional. (sumber data: wawancara).

\subsection{Analytic Hierarchy Process (AHP)}

Salah satu metode yang populer yang digunakan dalam melakukan rekomendasi sebuah keputusan adalah metode AHP yang mana metode ini memiliki prinsip agar dapat melakukan perbaikan dari metode yang telah ada sebelumnya. Adapun komponen utama yang dimiliki AHP ini adalah merupakan suatu hierarki fungsional dengan masukan berupa persepsi yang dimiliki manusia. (Permadi, 1992).

\subsection{Metode TOPSIS}

TOPSIS adalah metode pengambilan keputusan multikriteria yang pertama kali diperkenalkan oleh Kwangsun Yoon dan Hwang Ching-Lai (Ayrafedi, 2009). Classification dari method TOPSIS adalah kategori Multi Criteria Decision Making (MCDM) yaitu teknik pengambilan keputusan dari beberapa pilihan alternatif yang ada, khususnya Multi Criteria Decision Making (MCDM). TOPSIS bertujuan untuk menentukan solusi ideal positive and negative dan solusi ideal negative. Dalam TOPSIS, alternatif yang bik ialah yang sangat dekat dengan solusi ideal positif dan sangat jauh dari solusi ideal negatif (Himmah dkk, 2009).

\subsection{Penilaian}

Penilaian atau assessment merupakan unsur penting dalam pengendalian pendidikan. Penilaian atau assessment sebagai kegiatan menafsirkan data hasil pengukuran berdasarkan kriteria maupun aturan - aturan tertentu (Widoyoko, 2014: 30).

\section{ANALISIS DAN PERANCANGAN}

\subsection{Analisa Sistem}

Analisis sistem yang ada pada perancangan berisi kebutuhan fungsional, kebutuhan nonfungsional, dan analisis pengguna.

\subsection{Kebutuhan Fungsional}

Kebutuhan fungsional menggambarkan proses kegiatan yang akan diterapkan dalam sebuah sistem. Pada sistem seleksi calon karyawan baru ini memiliki kebutuhan fungsional sebagai berikut:

1. Sistem memiliki fasilitas login dengan memasukkan username dan password.

2. Sistem mampu menginputkan data calon karyawan baru yang akan diproses.

3. Sistem mampu melakukan proses AHP dan TOPSIS.

4. Sistem mampu memberikan hasil dari proses AHP dan TOPSIS penilaian karyawan baru dalam bentuk report.

\subsection{Kebutuhan Non Fungsional}

Adapun beberapa kebutuhan fungsional pada sistem seleksi karyawan baru ini memiliki kebutuhan non fungsional sebagai berikut adalah: 
1. Perangkat Keras (Hardware):

a. Laptop

2. Perangkat Lunak (Software):
a. Visual Studio Code

b. XAMPP

\section{c. Web Browser}

\subsection{Flowchart}

a. Flowchart Kombinasi metode AHP dan Topsis

Flowchart adalah suatu bagan dengan simbolsimbol tertentu yang menggambarkan urutan proses secara mendetail dan hubungan antara suatu proses (intruksi) dengan proses lainnya dalam suatu program.
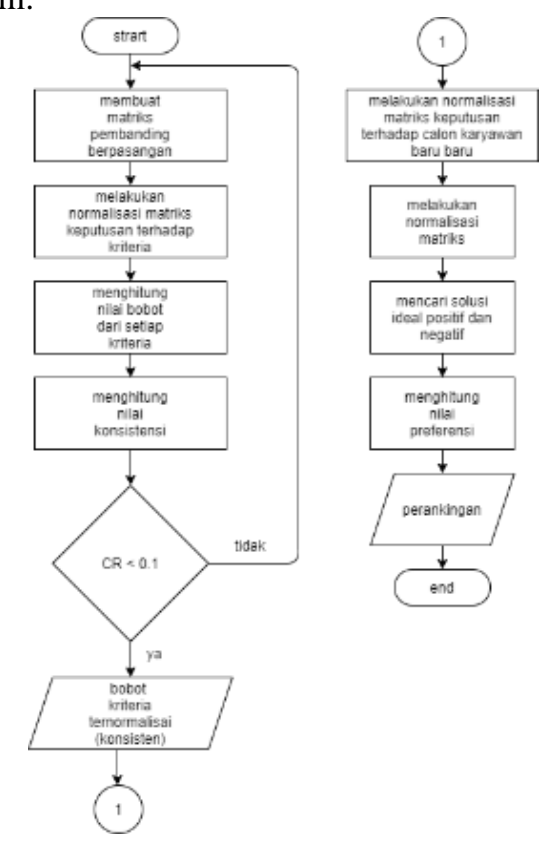

Gambar 1. Flowchart kombinasi metode AHP dan TOPSIS

Penjelasan:

Pada gambar 1 adalah Diagram alir perhitungan dari kombinasi metode AHP dengan TOPSIS dimana langkah awal yaitu membuat matriks perbandingan berpasangan kemudian kita lakukan normalisasi matriks, setelah matriks ternormalisasi kita menghitung bobot dari setiap kriteria, kemudian menghitung nilai konsistensi (CR) jika nilai $\mathrm{CR}<0.1$ maka bobot kriteria ternomalisasi jika tidak maka kita harus mengulang dari langkah awal kemudian setelah kita mendapatakan nilai yang konsisten pada metode AHP selanjutnya kita lakukan nomarlisasi matriks keputusan data karyawan baru kemudian kita menghitung solusi ideal positif dan solusi ideal negatif, kemudian menghitung jarak tiap alternatif dari solusi ideal positif dan solusi ideal negatif, setelah itu kita akan mendapatakan nilai preferensi yang nantinya bisa kita tentukan ranking dari tiap nilai yang diperoleh b. Flowchart Sistem

Flowchart sistem menjelaskan alur dari system yang dibuat. Mulai dari melakukan login dengan menginputkan username dan password, login akan dicek dahulu apakah username dan password yang di inputkan sudah benar. Jika benar maka admin akan akan masuk ke halaman тепи admin, namun jika salah admin akan tetap di halaman login. Flowchart penghitugan AHP membaca data karyawan baru dalam database. Data karyawan baru menampung data yang dibutuhkan yang sesuai kriteria. Selanjutnya pengambilan data bobot tiap tiap kriteria yang didapat pada database. Kemudian proses normalisasi data sesuai dengan kriteria yaitu (cost atau benefit). Setelah data dinormalisasi didapatkan, maka dilakukan perhitungan sehingga hasil akhir dari tiap-tiap alternatif. Kemudian perhitungan Technique for Order of Preference by Similarity to Ideal Solution (TOPSIS) menentukan solusi ideal yaitu terdapat ideal positif dan ideal negatif dan berikutnya menentukan jarak antara alternatif dengan solusi ideal (ideal positif dan ideal negatif). Langkah berikutnya adalah menentukan nilai preferensi pada setiap alternatif yang kemudian akan dirankingkan dari yang terbesar sampai terkecil, untuk melihat nilai dari tiap karyawan baru. Apabila proses yang dilakukan admin sudah selesai, admin dapat logout dan proses selesai. Untuk flowchart dapat dilihat pada gambar 2

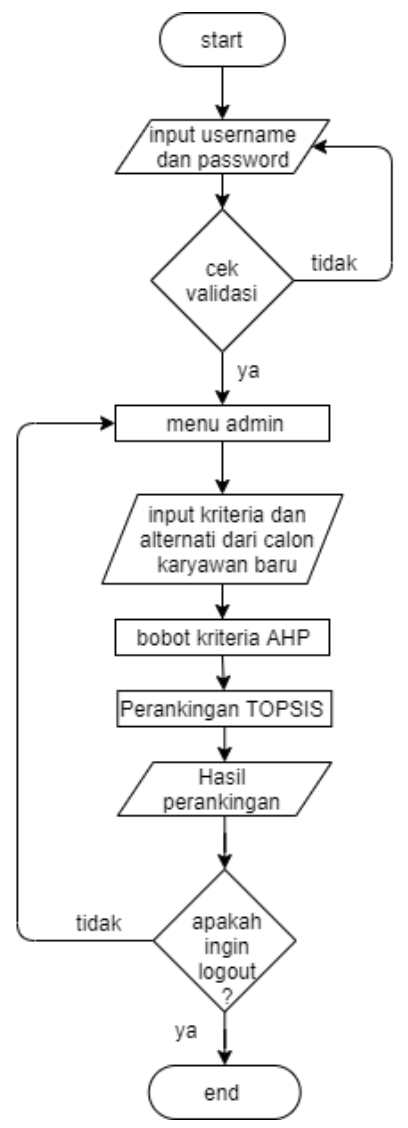

Gambar 2. Flowchart Sistem 


\subsection{Kriteria Penilaian Karyawan Baru}

Metode Analytic Hierarchy Process (AHP) digunakan untuk menstrukturisasi permasalahan keputusan menjadi bentuk hirarki dan menghitung bobot dari masingmasing faktor dan aktor, Sedangkan Technique for Order of Preference by Similarity to Ideal Solution (TOPSIS) digunakan untuk menghitung ranking dari solusi alternatif pada Analytic Hierarchy Process (AHP) yaitu memilih solusi alternatif terbaik berdasarkan jarak terdekat dari solusi ideal positif.

Penilaian karyawan baru yang harus memenuhi kriteria sebagai berikut:

Tabel 1. Kriteria calon karyawan baru

\begin{tabular}{|l|l|}
\hline No & Kriteria \\
\hline 1. & Sikap dan Perilaku \\
\hline 2. & Displin \& bertanggung jawab \\
\hline 3. & Pengalaman kerja \\
\hline 4. & Skill dan Keahlian \\
\hline 5. & Usia \\
\hline
\end{tabular}

\subsection{Tabel Bobot}

Adapun bobot yang digunakan untuk kriteria dalam penelitian ini adalah seperti pada tabel 3.2 berikut.

Tabel 2. bobot kriteria

\begin{tabular}{|c|c|c|c|c|}
\hline No & $\begin{array}{l}\text { Nama } \\
\text { Kriteria }\end{array}$ & $\begin{array}{c}\text { Nilai } \\
\text { Kriteria }\end{array}$ & $\begin{array}{l}\text { Bobot } \\
\text { kriteria }\end{array}$ & Keterangan \\
\hline \multirow[t]{4}{*}{1} & $\begin{array}{l}\text { Sikap } \\
\text { dan } \\
\text { Perilaku }\end{array}$ & $\begin{array}{l}\text { Sangat } \\
\text { Baik }\end{array}$ & 4 & $\begin{array}{l}\text { Calon karyawan dengan } \\
\text { sikap jujur, rajin dan } \\
\text { berperilaku dengan } \\
\text { sangat baik }\end{array}$ \\
\hline & & Baik & 3 & $\begin{array}{l}\text { Calon karyawan dengan } \\
\text { sikap jujur, rajin dan } \\
\text { berperilaku dengan baik }\end{array}$ \\
\hline & & $\begin{array}{l}\text { Cukup } \\
\text { Baik }\end{array}$ & 2 & $\begin{array}{l}\text { Calon karyawan dengan } \\
\text { sikap jujur, rajin dan } \\
\text { berperilaku dengan cukup } \\
\text { baik }\end{array}$ \\
\hline & & Kurang & 1 & $\begin{array}{l}\text { Calon karyawan dengan } \\
\text { sikap kurang jujur, rajin } \\
\text { dan berperilaku baik }\end{array}$ \\
\hline \multirow[t]{4}{*}{2} & $\begin{array}{c}\text { Displin } \\
\& \\
\text { bertangg } \\
\text { ung } \\
\text { jawab }\end{array}$ & $\begin{array}{l}\text { Sangat } \\
\text { Baik }\end{array}$ & 4 & $\begin{array}{l}\text { Calon karyawan dengan } \\
\text { memanajemen waktu } \\
\text { dengan sangat baik dan } \\
\text { bertanggung jawab }\end{array}$ \\
\hline & & Baik & 3 & $\begin{array}{l}\text { Calon karyawan dengan } \\
\text { memanajemen waktu } \\
\text { dengan baik dan } \\
\text { bertanggung jawab }\end{array}$ \\
\hline & & $\begin{array}{l}\text { Cukup } \\
\text { Baik }\end{array}$ & 2 & $\begin{array}{l}\text { Calon karyawan dengan } \\
\text { memanajemen waktu } \\
\text { dengan cukup baik dan } \\
\text { bertanggung jawab }\end{array}$ \\
\hline & & Kurang & 1 & $\begin{array}{l}\text { Calon karyawan dengan } \\
\text { memanajemen waktu } \\
\text { dengan kurang baik dan } \\
\text { bertanggung jawab }\end{array}$ \\
\hline \multirow[t]{2}{*}{3} & $\begin{array}{l}\text { Pengala } \\
\text { man } \\
\text { kerja }\end{array}$ & $\begin{array}{l}\text { Sangat } \\
\text { Baik }\end{array}$ & 4 & $\begin{array}{l}\text { Pengalaman kerja diatas } \\
3 \text { tahun }\end{array}$ \\
\hline & & Baik & 3 & $\begin{array}{l}\text { Pengalaman kerja diatas } \\
2 \text { tahun }\end{array}$ \\
\hline
\end{tabular}

\begin{tabular}{|c|c|c|c|c|}
\hline & & $\begin{array}{l}\text { Cukup } \\
\text { Baik }\end{array}$ & 2 & $\begin{array}{l}\text { Pengalaman kerja diatas } \\
1 \text { tahun }\end{array}$ \\
\hline & & Kurang & 1 & $\begin{array}{l}\text { Pengalaman kerja di } \\
\text { bawah } 1 \text { tahun }\end{array}$ \\
\hline \multirow[t]{4}{*}{4} & $\begin{array}{l}\text { Skill dan } \\
\text { Keahlian }\end{array}$ & $\begin{array}{l}\text { Sangat } \\
\text { Baik }\end{array}$ & 4 & $\begin{array}{l}\text { Calon karyawan harus } \\
\text { memiliki kemampuan } \\
\text { berkomunikasi dan } \\
\text { beradaptasi dengan } \\
\text { sangat baik }\end{array}$ \\
\hline & & Baik & 3 & $\begin{array}{l}\text { Calon karyawan harus } \\
\text { memiliki kemampuan } \\
\text { berkomunikasi dan } \\
\text { beradaptasi dengan baik }\end{array}$ \\
\hline & & $\begin{array}{c}\text { Cukup } \\
\text { Baik }\end{array}$ & 2 & $\begin{array}{l}\text { Calon karyawan harus } \\
\text { memiliki kemampuan } \\
\text { berkomunikasi dan } \\
\text { beradaptasi dengan cukup } \\
\text { baik }\end{array}$ \\
\hline & & Kurang & 1 & $\begin{array}{l}\text { Calon karyawan harus } \\
\text { memiliki kemampuan } \\
\text { berkomunikasi dan } \\
\text { beradaptasi dengan } \\
\text { kurang baik }\end{array}$ \\
\hline \multirow[t]{3}{*}{5} & \multirow[t]{2}{*}{ Usia } & $\begin{array}{l}20-30 \\
\text { tahun }\end{array}$ & 4 & $\begin{array}{l}\text { Karyawan muda } \\
\text { mempunyai fisik yang } \\
\text { lebih kuat, dinamis dan } \\
\text { kreatif }\end{array}$ \\
\hline & & $\begin{array}{c}\text { Di } \\
\text { bawah } \\
19 \\
\text { tahun }\end{array}$ & 3 & $\begin{array}{l}\text { Karyawan muda } \\
\text { mempunyai fisik yang } \\
\text { lebih kuat, pola berpikir } \\
\text { belum dewasa }\end{array}$ \\
\hline & & $\begin{array}{l}\text { Di atas } \\
30 \\
\text { tahun }\end{array}$ & 2 & $\begin{array}{l}\text { Karyawan tua kondisi } \\
\text { fisiknya kurang, tetapi } \\
\text { bekerja ulet, tanggung } \\
\text { jawabnya besar }\end{array}$ \\
\hline
\end{tabular}

\section{HASIL DAN PEMBAHASAN}

\subsection{Halaman Login}

Pada bagian ini, admin harus harus login terlebih dahulu agar dapat mengakses sistem seperti gambar dibawah ini.

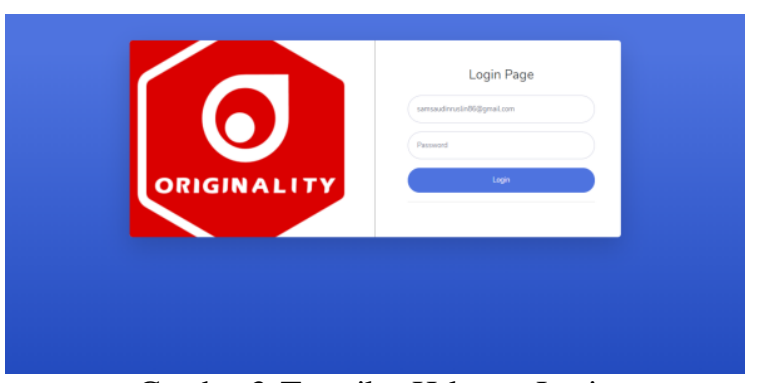

Gambar 3. Tampilan Halaman Login

\subsection{Halaman Dashboard}

Pada halaman ini, terdapat beberapa menu lainnya seperti menu pada saat ini yaitu dashboard, data kriteria, data alternatif, analisa data kriteria, perankingan, cetak laporan seperti pada gambar 4.2 dibawah ini. 


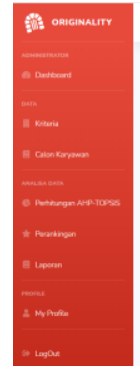

Gambar 4. Tampilan Halaman Dashboard

\subsection{Halaman kriteria}

Pada halaman ini, akan ditampilkan kriteria calon karyawan baru.
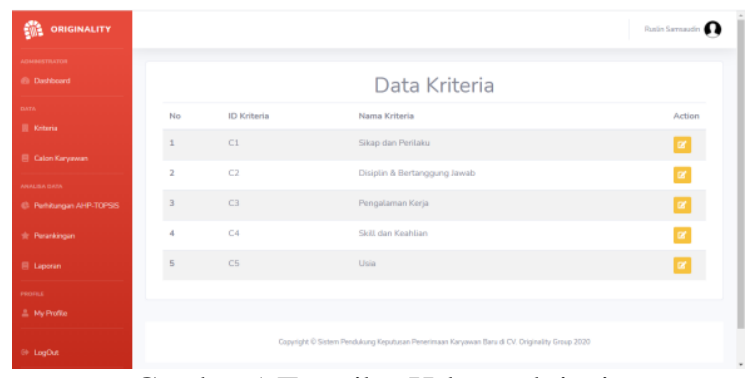

Gambar 5. Tampilan Halaman kriteria

\subsection{Halaman data karyawan}

Pada halaman ini, akan ditunjukkan data alternatif atau nama-nama calon karyawan baru.
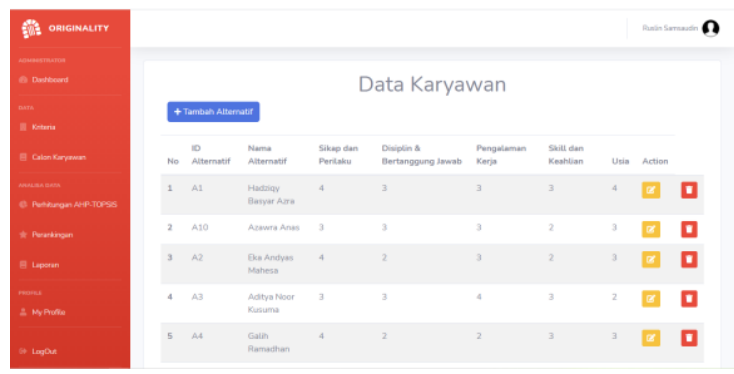

Gambar 6. Tampilan Halaman calon karyawan

\subsection{Halaman perhitungan AHP-TOPSIS}

Halaman ini akan menampilkan proses perhitungan AHP
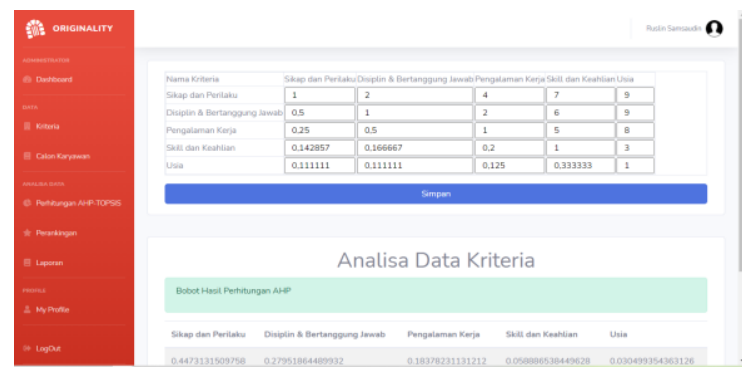

Gambar 7. Tampilan Halaman perhitungan AHP-TOPSIS

\subsection{Halaman perangkingan}

Halaman ini menampilkan hasil dari proses perhitungan AHP- TOPSIS

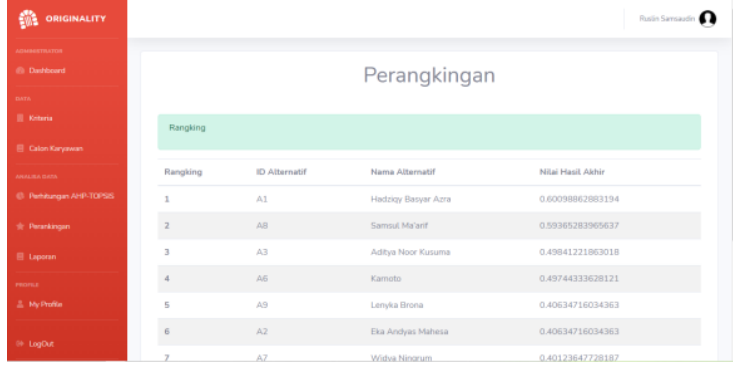

Gambar 8. Tampilan Halaman analisa data kriteria

\subsection{Pengujian Fungsional}

Pengujian fungsional sistem dijalankan untuk pengujian fitur-fitur yang ada pada implementasi metode AHP dan TOPSIS untuk seleksi calon karyawan baru pada CV. Originality Group. Hasil pengujian fungsional sistem ditunjukan dalam Tabel 3

Tabel 3. Tabel Pengujian Fungsional

\begin{tabular}{|l|l|l|l|}
\hline No & Fungsi Yang Diuji & Berhasil & Gagal \\
\hline 1 & Login & $\checkmark$ & - \\
\hline 2 & Halaman Dasboard & $\checkmark$ & - \\
\hline 3 & Halaman Data Kriteria & $\checkmark$ & - \\
\hline & a. Tambah Data Kriteria & $\checkmark$ & - \\
\hline & b. Edit Data Kriteria & $\checkmark$ & - \\
\hline & c. Hapus Data Kriteria & $\checkmark$ & - \\
\hline 4 & Halaman Data Alternatif & $\checkmark$ & - \\
\hline & a. Tambah Data Alternatif & $\checkmark$ & - \\
\hline & b. Edit Data Alternatif & $\checkmark$ & - \\
\hline & c. Hapus Data Alternatif & $\checkmark$ & - \\
\hline 5 & Halaman Analisa Alternatif & $\checkmark$ & - \\
\hline & a. Halaman Perangkingan & $\checkmark$ & - \\
\hline & b. Halaman Laporan & $\checkmark$ & - \\
\hline 6 & Halaman Profil & $\checkmark$ & - \\
\hline 7 & Logout & $\checkmark$ & - \\
\hline
\end{tabular}

\section{Keterangan :}

$>\quad \checkmark$ : Berhasil

$>\quad$-: Gagal

Berdasarkan hasil pungujian fungsional yang telah dilakukan mendapatkan hasil bahwa semua halaman, button dan laporan pada implementasi metode AHP dan TOPSIS untuk seleksi calon karyawan baru pada CV. Originality Group yang dibuat telah berhasil dan berjalan dengan baik

\subsection{Pengujian Browser}

Tabel 4. Tabel Pengujian Browser

\begin{tabular}{|c|l|c|c|}
\hline No & \multicolumn{1}{|c|}{ Fungsi Yang Diuji } & $\begin{array}{c}\text { Microsoft } \\
\text { Edge }\end{array}$ & $\begin{array}{c}\text { Google } \\
\text { Chrome }\end{array}$ \\
\hline 1 & Login & $\checkmark$ & $\checkmark$ \\
\hline 2 & Halaman Dasboard & $\checkmark$ & $\checkmark$ \\
\hline 3 & Halaman Data Kriteria & $\checkmark$ & $\checkmark$ \\
\hline & a. Tambah Data Kriteria & $\checkmark$ & $\checkmark$ \\
\hline & b. Edit Data Kriteria & $\checkmark$ & $\checkmark$ \\
\hline & c. Hapus Data Kriteria & $\checkmark$ & $\checkmark$ \\
\hline 4 & Halaman Data Alternatif & $\checkmark$ & $\checkmark$ \\
\hline & a. Tambah Data Alternatif & $\checkmark$ & $\checkmark$ \\
\hline & b. Edit Data Alternatif & $\checkmark$ & $\checkmark$ \\
\hline & Hapus Data Alternatif & $\checkmark$ & $\checkmark$ \\
\hline 5 & Halaman Analisa Alternatif & $\checkmark$ & $\checkmark$ \\
\hline & Halaman Perangkingan & $\checkmark$ & $\checkmark$ \\
\hline & Halaman Laporan & $\checkmark$ & $\checkmark$ \\
\hline 6 & Halaman Profil & $\checkmark$ & $\checkmark$ \\
\hline 7 & Logout & $\checkmark$ & $\checkmark$ \\
\hline
\end{tabular}


Keterangan :

$\checkmark$ : Berhasil

$\mathrm{X}$ : Gagal

\subsection{Perhitungan Metode AHP dan TOPSIS}

Berikut ini adalah langka-langkah perhitungan metode AHP dilanjut dengan TOPSIS.

1. Membuat matrix perbandingan berpasangan pada kriteria

2. Menghitung vector eigen(bobot) dari setiap matriks perbandingan berpasangan, berikut adalah hasil dari perhitungan menentukan bobot
Tabel 5. Matriks Perbandingan kriteria

\begin{tabular}{|c|c|c|c|c|c|}
\hline Kriteria & 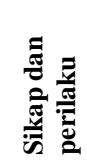 & 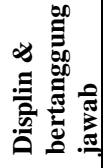 & 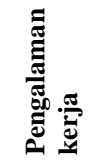 & 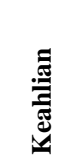 & 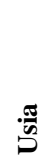 \\
\hline Sikap dan perilaku & 1 & 2 & 4 & 7 & 9 \\
\hline $\begin{array}{l}\text { Displin \& } \\
\text { bertanggung jawab }\end{array}$ & 0.5 & 1 & 2 & 6 & 9 \\
\hline Pengalaman kerja & 0.3 & 0.5 & 1 & 5 & 8 \\
\hline Keahlian & 0.143 & 0.167 & 0.2 & 1 & 3 \\
\hline Usia & 0.11 & 0.111 & 0.125 & 0.33 & 1 \\
\hline
\end{tabular}

Tabel 6. Nilai Bobot Pada Kriteria.

\begin{tabular}{|c|c|c|c|c|c|c|}
\hline \multicolumn{5}{|c|}{ Nilai Eigen } & Jumlah & $\begin{array}{c}\text { rata- } \\
\text { rata }\end{array}$ \\
\hline 0.49901 & 0.529412 & 0.546075 & 0.49901 & 0.529412 & 0.546075 & 0.49901 \\
\hline 0.249505 & 0.264706 & 0.273038 & 0.249505 & 0.264706 & 0.273038 & 0.249505 \\
\hline 0.124752 & 0.132353 & 0.136519 & 0.124752 & 0.132353 & 0.136519 & 0.124752 \\
\hline 0.071287 & 0.044118 & 0.027304 & 0.071287 & 0.044118 & 0.027304 & 0.071287 \\
\hline 0.055446 & 0.029412 & 0.017065 & 0.055446 & 0.029412 & 0.017065 & 0.055446 \\
\hline \multicolumn{7}{|c}{} \\
\hline
\end{tabular}

Table 7. nilai index rasio

\begin{tabular}{|c|c|c|c|c|c|c|c|c|c|c|c|}
\hline $\mathrm{N}$ & 1 & 2 & 3 & 4 & 5 & 6 & 7 & 8 & 9 & 10 & 11 \\
\hline $\mathrm{RI}$ & 0 & 0 & 0.58 & 0.9 & 1.12 & 2.24 & 1.32 & 1.41 & 1.45 & 1.49 & 1.51 \\
\hline
\end{tabular}

3. Memeriksa konsistensi hirarki dengan melihat indeks rasio, berikut adalah nilai indeks rasio

4. Hasil dari Menghitung nilai CI dan CR

Table 8. uji konsistensi

\begin{tabular}{|c|c|}
\hline $\mathrm{CI}=$ (lamda Max-n)/(n-1) & Hasil \\
\hline lamda Max $=$ & 11.3009499 \\
\hline $\mathrm{CI}=$ & 0.14454999 \\
\hline $\mathrm{CR}=\mathrm{CI} / \mathrm{IR}$ & 0.09701341 \\
\hline
\end{tabular}

Karena nilai $\mathrm{CR} \leq 0,1$ maka bobot sudah konsisten dan dapat dilanjutkan ke proses perangkingan menggunakan metode TOPSIS.

5. Proses Perangkingan dengan metode TOPSIS dengan data penilaian karyawan baru. Membuat Matriks Keputusan terhadap data penilaian karyawan baru.
Table 9. matrik keputusan

\begin{tabular}{|c|c|c|c|c|c|}
\hline NAMA & 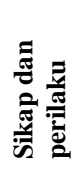 & 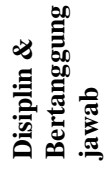 & 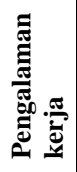 & 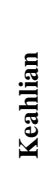 & 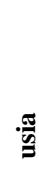 \\
\hline Hadziqy Basyar Azra & 4 & 3 & 3 & 3 & 4 \\
\hline Eka Andyas Mahesa & 4 & 2 & 3 & 2 & 3 \\
\hline Aditya Noor Kusuma & 3 & 3 & 4 & 3 & 2 \\
\hline Galih Ramadhan & 4 & 2 & 2 & 3 & 3 \\
\hline Ahmad Khadziq & 3 & 3 & 3 & 2 & 3 \\
\hline Karnoto & 4 & 3 & 2 & 2 & 2 \\
\hline Widya Ningrum & 3 & 3 & 3 & 2 & 4 \\
\hline Samsul Ma'arif & 3 & 4 & 3 & 3 & 3 \\
\hline Lenyka Brona & 4 & 2 & 3 & 2 & 3 \\
\hline Azawra Anas & 3 & 3 & 3 & 2 & 3 \\
\hline
\end{tabular}

6. Membuat pembagi dan melakukan normalisasi matriks.

Table 10. pembagi dan matrik keputusan ternormalisasi

\begin{tabular}{|c|c|c|c|c|c|}
\hline PEMBAGI & 11.18033989 & 9.055385138 & 9.327379053 & 7.745967 & 9.69536 \\
\hline & Sikap dan perilaku & Disiplin \& Bertanggung jawab & Pengalaman kerja & Keahlian & usia \\
\hline Hadziqy Basyar Azra & 0.357770876 & 0.331294578 & 0.32163376 & 0.387298 & 0.412568 \\
\hline Eka Andyas Mahesa & 0.357770876 & 0.220863052 & 0.32163376 & 0.258199 & 0.309426 \\
\hline Aditya Noor Kusuma & 0.268328157 & 0.331294578 & 0.428845014 & 0.387298 & 0.206284 \\
\hline Galih Ramadhan & 0.357770876 & 0.220863052 & 0.214422507 & 0.387298 & 0.309426 \\
\hline Ahmad Khadziq & 0.268328157 & 0.331294578 & 0.32163376 & 0.258199 & 0.309426 \\
\hline Karnoto & 0.357770876 & 0.331294578 & 0.214422507 & 0.258199 & 0.206284 \\
\hline Widya Ningrum & 0.268328157 & 0.331294578 & 0.32163376 & 0.258199 & 0.412568 \\
\hline Samsul Ma'arif & 0.268328157 & 0.441726104 & 0.32163376 & 0.387298 & 0.309426 \\
\hline Lenyka Brona & 0.357770876 & 0.220863052 & 0.32163376 & 0.258199 & 0.309426 \\
\hline Azawra Anas & 0.268328157 & 0.331294578 & 0.32163376 & 0.258199 & 0.309426 \\
\hline
\end{tabular}


7. Menghitung matriks keputusan ternormalisasi dan terbobot yang di dapat dari perhitungan metode topsis.

Table 11. matrik keputusan ternormalisasi terbobot

\begin{tabular}{|l|c|c|c|c|c|}
\hline \multicolumn{1}{|c|}{ NAMA } & Sikap dan perilaku & Disiplin \& Bertanggung jawab & Pengalaman kerja & Keahlian & usia \\
\hline Hadziqy Basyar Azra & 0.160035615 & 0.09260301 & 0.059110595 & 0.022807 & 0.012583 \\
\hline Eka Andyas Mahesa & 0.160035615 & 0.06173534 & 0.059110595 & 0.015204 & 0.009437 \\
\hline Aditya Noor Kusuma & 0.120026711 & 0.09260301 & 0.078814127 & 0.022807 & 0.006292 \\
\hline Galih Ramadhan & 0.160035615 & 0.06173534 & 0.039407063 & 0.022807 & 0.009437 \\
\hline Ahmad Khadziq & 0.120026711 & 0.09260301 & 0.059110595 & 0.015204 & 0.009437 \\
\hline Karnoto & 0.160035615 & 0.09260301 & 0.039407063 & 0.015204 & 0.006292 \\
\hline Widya Ningrum & 0.120026711 & 0.09260301 & 0.059110595 & 0.015204 & 0.012583 \\
\hline Samsul Ma'arif & 0.120026711 & 0.12347068 & 0.059110595 & 0.022807 & 0.009437 \\
\hline Lenyka Brona & 0.160035615 & 0.06173534 & 0.059110595 & 0.015204 & 0.009437 \\
\hline Azawra Anas & 0.120026711 & 0.09260301 & 0.059110595 & 0.015204 & 0.009437 \\
\hline
\end{tabular}

8. Mencari solusi ideal positif dan negative.

Table 12. solusi ideal positif dan solusi ideal negatif

\begin{tabular}{|l|c|c|c|c|c|}
\hline Max & 0.160035615 & 0.12347068 & 0.078814127 & 0.022807 & 0.012583 \\
\hline \multicolumn{7}{|c|}{} \\
\hline Min & 0.120026711 & 0.06173534 & 0.039407063 & 0.015204 & 0.006292 \\
\hline
\end{tabular}

9. Menentukan jarak solusi ideal posotif dan negative, hasil dari perhitungan dapat dilihat pada table berikut:

Table13. jarak solusi ideal positif dan negatif

\begin{tabular}{|c|l|c|}
\hline D+ & & $\mathrm{D}-$ \\
\hline 2.268628241 & Hadziqy Basyar Azra & 6.803093 \\
\hline 3.454391466 & Eka Andyas Mahesa & 4.077141 \\
\hline 7.112808751 & Aditya Noor Kusuma & 1.231796 \\
\hline 4.21427483 & Galih Ramadhan & 3.387685 \\
\hline 3.437545107 & Ahmad Khadziq & 4.091355 \\
\hline 6.863449327 & Karnoto & 2.236612 \\
\hline 0.616677488 & Widya Ningrum & 7.144821 \\
\hline 4.096238246 & Samsul Ma'arif & 3.521517 \\
\hline 3.454391466 & Lenyka Brona & 4.077141 \\
\hline 3.437545107 & Azawra Anas & 4.091355 \\
\hline
\end{tabular}

10. Menghitung nilai preferensi dari setiap alternative,
Table 14. menghitung preferensi

\begin{tabular}{|l|c|}
\hline \multicolumn{1}{|c|}{ Alternatif } & Hasil \\
\hline Hadziqy Basyar Azra & 0.600863039 \\
\hline Eka Andyas Mahesa & 0.406321628 \\
\hline Aditya Noor Kusuma & 0.498565647 \\
\hline Galih Ramadhan & 0.357815273 \\
\hline Ahmad Khadziq & 0.401197479 \\
\hline Karnoto & 0.497596172 \\
\hline Widya Ningrum & 0.404207893 \\
\hline Samsul Ma'arif & 0.593678372 \\
\hline Lenyka Brona & 0.406321628 \\
\hline Azawra Anas & 0.401197479 \\
\hline
\end{tabular}

\subsection{Pengujian Akurasi Metode}

Confusion matrix merupakan salah satu metode yang dapat digunakan untuk mengukur kinerja suatu metode pendukug keputusan. Pada dasarnya confusion matrix mengandung informasi yang membandingkan hasil pendukung keputusan yang dilakukan oleh sistem dengan hasil pendukung keputusan yang seharusnya.

Akurasi $=\frac{T P+T N}{T P+T N+F P+F N}$

Tabel 15. Pengujian akurasi metode

\begin{tabular}{|c|c|c|c|c|c|c|c|}
\hline No & nama & $\begin{array}{c}\text { Sikap dan } \\
\text { perilaku }\end{array}$ & $\begin{array}{c}\text { Disiplin \& } \\
\text { bertanggung jawab }\end{array}$ & $\begin{array}{c}\text { Pengalaman } \\
\text { kerja }\end{array}$ & $\begin{array}{c}\text { Keahli } \\
\text { an }\end{array}$ & usia & $\begin{array}{c}\text { ketera } \\
\text { ngan }\end{array}$ \\
\hline 1 & $\begin{array}{l}\text { Hadziqy } \\
\text { Basyar Azra }\end{array}$ & Sangat Baik & Baik & Baik & Baik & 25 tahun - 30 tahun & sesuai \\
\hline 2 & $\begin{array}{l}\text { Eka Andyas } \\
\text { Mahesa }\end{array}$ & Sangat Baik & Cukup Baik & Baik & $\begin{array}{l}\text { Cukup } \\
\text { Baik }\end{array}$ & 20 tahun -24 tahun & sesuai \\
\hline 3 & $\begin{array}{l}\text { Aditya Noor } \\
\text { Kusuma }\end{array}$ & Baik & Baik & Sangat Baik & Baik & 18 tahun -20 tahun & sesuai \\
\hline 4 & $\begin{array}{l}\text { Galih } \\
\text { Ramadhan }\end{array}$ & Sangat Baik & Cukup Baik & Cukup Baik & Baik & 20 tahun -24 tahun & $\begin{array}{l}\text { Tidak } \\
\text { sesuai }\end{array}$ \\
\hline 5 & $\begin{array}{l}\text { Ahmad } \\
\text { Khadziq }\end{array}$ & Baik & Baik & Baik & $\begin{array}{c}\text { Cukup } \\
\text { Baik }\end{array}$ & 20 tahun -24 tahun & sesuai \\
\hline 6 & Karnoto & Sangat Baik & Baik & Cukup Baik & $\begin{array}{l}\text { Cukup } \\
\text { Baik }\end{array}$ & 18 tahun -20 tahun & sesuai \\
\hline
\end{tabular}




\begin{tabular}{|c|l|c|c|c|c|c|c|}
\hline 7 & $\begin{array}{l}\text { Widya } \\
\text { Ningrum }\end{array}$ & Baik & Baik & Baik & $\begin{array}{c}\text { Cukup } \\
\text { Baik }\end{array}$ & 25 tahun - 30 tahun & sesuai \\
\hline 8 & Samsul Ma'arif & Baik & Sangat Baik & Baik & Baik & 20 tahun - 24 tahun & sesuai \\
\hline 9 & Lenyka Brona & Lenyka Brona & Sangat Baik & Cukup Baik & Baik & $\begin{array}{c}\text { Cukup Baik } \\
\text { sesuai }\end{array}$ \\
\hline 10 & Azawra Anas & Baik & Baik & Baik & $\begin{array}{c}\text { Cukup } \\
\text { Baik }\end{array}$ & 20 tahun - 24 tahun & sesuai \\
\hline
\end{tabular}

Tabel 16. Data pengujian akurasi metode

\begin{tabular}{|c|c|}
\hline TP (True Positif) & FP (False Positif) \\
\hline 8 & 2 \\
\hline FN (False Negatif) & TN (True Negatif) \\
\hline 0 & 0 \\
\hline
\end{tabular}

$$
\begin{aligned}
\text { Akurasi }= & \frac{T P+T N}{T P+T N+F P+F N} \\
\text { Akurasi }= & \frac{8+0}{8+0+2+0} \\
& =0.8 * 100 \%=80 \%
\end{aligned}
$$

Dapat disimpulkan bahwa metode AHP-TOPSIS pada penialaian karyawan dengan uji akurasi confusion matrix nilai yang sesuai terdapat 8 (TP), untuk nilai klasifikasi yang salah adalah 2 (FP), nilai dari $\mathrm{FN}$ adalah 0 dan untuk nilai $\mathrm{TN}$ yaitu 0 sehingga didapatkan nilai akurasi dari hasil perhitungan yaitu $80 \%$ Accuracy

\section{KESIMPULAN DAN SARAN}

\subsection{Kesimpulan}

Kesimpulan yang dapat diuraikan dari hasil pembuatan implementasi metode AHP dan TOPSIS untuk seleksi calon karyawan baru pada CV. Originality Group berbasis web yaitu:

1. Berdasarkan hasil pengujian fungsionalitas pada aplikasi implementasi metode AHP dan TOPSIS untuk seleksi calon karyawan baru pada CV. Originality Group dapat dijalankan dengan baik pada browser web.

2. Berdasarkan hasil pengujian aplikasi dengan menggunakan 2 browser yang berbeda, semua tampilan dan fungsi aplikasi dapat berjalan $100 \%$ pada 2 browser yaitu, Microsoft Edge Version 91.0.864.54 (Official build) (64-bit) dan Google Chrome Versi 91.0.4472.114 (Build Resmi) (64 bit).

3. Hasil pengujian akurasi tersebut Dapat disimpulkan metode AHP-TOPSIS pada penialaian karyawan dengan uji akurasi confusion matrix nilai yang sesuai terdapat 8 (TP), untuk nilai klasifikasi yang salah adalah 2 (FP), nilai dari FN adalah 0 dan untuk nilai TN yaitu 0 sehingga didapatkan nilai akurasi dari hasil perhitungan yaitu $80 \%$ Accuracy.

\subsection{Saran}

Agar pengembangan sistem yang telah dibuat menjadi lebih baik kedepannya, maka ada beberapa saran yang bisa diberikan, yaitu:
1. Metode AHP dan TOPSIS bukan satu-satunya untuk menyelesaikan masalah multi kriteria yang dapat digunakan, direkomendasikan untuk mencoba menggunakan metode penggabungan yang lain untuk mendukung keputusan yang lebih efektif..

2. Diharapkan system dapat dikembangkan berbasis mobile/ios.

\section{DAFTAR PUSTAKA}

[1] Achmad Sidik. (2021). Implementasi AHP TOPSIS Alternatif Penentuan Jabatan di STMIK GLOBAL. AJCSR (Academic Journal of Computer Science Research), Vol. 3 No. 1, Januari 2021.

[2] Deddy Kusbianto. (2019). Implementasi Metode AHP dan TOPSIS untuk Rekomendasi Wisata Kota Batu. Diakses 20 mei 2021.

[3] Fita Lathifatul Mu'asyaroh. (2016). IMPLEMENTASI ALGORITMA GENETIKA DALAM OPTIMASI MODEL AHP DAN TOPSIS UNTUK PENENTUAN KELAYAKAN PENGISIAN BIBIT AYAM BROILER DI KANDANG PETERNAK. Jurnal Teknologi Informasi dan Ilmu Komputer (JTIIK), Vol. 3, No. 4, Desember 2016.

[4] Moh. Zulkifli Katili. (2021). Impelementasi Metode AHP-TOPSIS Dalam Sistem Pendukung Rekomendasi Mahasiswa Berprestasi. JAMBURA JOURNAL OF INFORMATICS, Vol. 3, No. 1, April 2021.

[5] Muhammad Auva Al-Marom. (2021). Sistem Penunjang Keputusan Rekomendasi Kelulusan dan Pemeringkatan Santri Menggunakan Metode AHP-TOPSIS. Jurnal Ilmiah MEDIA SISFO, Vol. 15, No. 1, April 2021.

[6] Muhamad Fahrur Rozi. (2019). Sistem Pendukung Keputusan Penerimaan Pegawai Baru menggunakan Metode AHP dan TOPSIS. Jurnal Pengembangan Teknologi Informasi dan Ilmu Komputer, Vol. 3, No. 9, September 2019.

[7] Putu Praba Santika. (2019). SISTEM PENDUKUNG KEPUTUSAN PENERIMAAN KARYAWAN DENGAN METODE AHP TOPSIS (Studi Kasus: PT. Global Retailindo Pratama). SINTECH Journal(Science and Information Technology), Volume 1 No 1, April 2018.

[8] Roby Muhammad Ikhsan. (2021). IMPLEMENTASI METODE ANALITYCAL HIERARCHY PROCESS (AHP) DAN TOPSIS UNTUK PEMILIHAN KAMERA. Jurnal 
Teknik Informatika dan Sistem Informasi, Vol. 8, No. 1, Maret 2021.

[9] Silvi Dwi Megafani. (2021). SISTEM PENDUKUNG KEPUTUSAN PEREKRUTAN ANGGOTA BARU RESIMEN MAHASISWA DI ITN MALANG MENGGUNAKAN KOMBINASI METODE AHP dan TOPSIS. JATI (Jurnal Mahasiswa Teknik Informatika), Volume 5, No.1, Desember 2021. 